\title{
Mapuche-huilliches e hispano- criollos en Valdivia. Cartas de petición y procesos de articulación en el período colonial tardío
}

Aceptación: Diciembre - 2007

Aprobación: Abril - 2008

María Pía Poblete Segú*

\section{RESUMEN}

Se analiza un conjunto de "cartas de petición" enviadas por caciques o "ulmenes" mapuche-huilliches a autoridades de la Plaza de Valdivia en el período colonial tardío. Estos escritos, aunque escasos en número, revelan nuevas dimensiones para explorar las relaciones interétnicas en la jurisdicción colonial de Valdivia. Su análisis ilumina las formas en que los mapuche-huilliches han usado y valorado los documentos escritos. Se argumenta que la producción de estos escritos fue una práctica frecuente para un sector de la sociedad mapuche-huilliche en este período, que no se explica solo por la integración de hijos de caciques en colegios, sino también a partir de la temprana y continua interacción entre hispano-criollos y mapuchehuilliches.

PALABRAS CLAVE: mapuche-huilliches, escritura indígena, relaciones interétnicas, Valdivia colonial.

\section{ABSTRACT}

Petition letters sent to authorities in the government of Valdivia, during the late colonial period by mapuche-huilliche caciques or "ulmenes" are analized. Although scarce, these letters provide a different approach to explore interethnic relationships in the colonial district of Valdivia. The analysis of these documents illustrates the different ways the mapuche-huilliche people have used and valued written documents. It is argued that their production was a frequent practice for a group of them, which cannot be explained by the education received in schools by their children only, but also by the early and continuous interaction between spanish and mapuche-huilliche people.

KEY WORDS: mapuche-huilliches, indian writing, interethnic relationships, Valdivia colonial.

Instituto de Ciencias Sociales, Universidad Austral de Chile, ppoblete@uach.cl Este trabajo ha sido elaborado como parte del Proyecto Fondecyt $N^{\circ}$ 1050309. La autora agradece los comentarios del Dr. Jorge Hidalgo L. 
Introducción

Las relaciones entre hispanos y mapuches se construyeron en múltiples contextos. Entre estos se han descrito diversos encuentros 'diplomáticos' o "parlamentos" entre representantes de ambas sociedades ${ }^{1}$. En Valdivia, territorio mapuche-huilliche ${ }^{2}$, estos encuentros diplomáticos consistían en visitas anuales a la Plaza de los caciques "amistados"; "parlas" en Valdivia o en el territorio mapuchehuilliche para confirmar el estado de paz, establecer misiones y presentar nuevos caciques amigos, y un parlamento general que se realizaba una vez durante cada mandato de un gobernador reuniendo caciques y "ulmenes" ${ }^{3}$ de la jurisdicción. Junto a estos encuentros interétnicos, altamente ritualizados, estuvieron aquellos contactos cotidianos que llevaron al mestizaje e integración de grupos e individuos indígenas en la "clase de españoles" 40 a la inversa. Sin embargo, como sabemos desde Barth (1976), la interacción social no disuelve los límites entre los grupos étnicos, más bien los confirma y actualiza. De este modo, la circulación de individuos entre la Plaza de Valdivia y el territorio indígena independiente movilizó todo tipo de recursos materiales e informaciones en ambas direcciones, desdibujando diferencias y formando nuevas realidades, pero los límites sociales no desaparecieron, solo se desplazaron cambiando las líneas de demarcación entre el mundo "interno" de cada sociedad y el universo "externo", entre lo local y lo global (cf. Comaroff y Comaroff, 1992: 98). Las relaciones entre misioneros e indígenas, entre indígenas y soldados, entre caciques y gobernadores de la Plaza acontecieron en un contexto de luchas de los agentes por la definición de esferas relativamente autónomas para obtener control sobre espacios en disputa. En este escenario los huilliches incorporaron tempranamente el conjunto de derechos que la Corona establecía para las sociedades nativas usando estratégicamente la escritura $\mathrm{y}$, como otros grupos en espacios muy lejanos, utilizaron las "fisuras percibidas en las clases gobernantes, elevando [...] quejas contra las autoridades locales a las autoridades centrales" (Van Voss, 2001:6) presentando demandas escritas y solicitando documentos para asegurar los acuerdos alcanzados, maniobrando a través de cartas de petición en distintos niveles de las estructuras jurídico-administrativas y políticas hispanas.

\section{La escritura indígena en Valdivia colonial ${ }^{5}$}

"la escritura puede ser todo lo que nosotros logremos leer en ella": ante todo, lo que concierne a los hombres que la han usado y su mundo .

1 Sobre parlamentos en la Araucanía ver Méndez, 1982; Villalobos, 1995; Zavala, 1998. Para la jurisdicción de Valdivia no existen investigaciones sobre los parlamentos, aunque han sido tratados por Guarda, 2000 y Vergara, 2005. Este último autor señala que "....a diferencia de lo que ocurrió en la Araucanía, los parlamentos en Valdivia parecen no haber sido nunca 'universales' (la expresión es de Ambrosio O’Higgins), es decir no congregaron al conjunto de agrupaciones indígenas de la región" (2005: 107). En los parlamentos que detalla este autor, todos los de la jurisdicción de Valdivia corresponden a reuniones citadas con algún fin particular: presentación de caciques de Río Bueno, preparativos y confirmación de la apertura del camino a Chiloé, parlamentos posteriores al alzamiento de 1792. Guarda (2000:16) entrega las listas de agasajos y gastos de estos parlamentos, destacando que algunos alcanzaban un gasto considerable.

2 Se considera territorio mapuche-huilliche o huilliche aquel situado al sur del río Toltén, en este habita la sección meridional del pueblo mapuche, los mapuche-huilliches o huilliches. Esta división ha variado históricamente, pero se seguirá aquí, porque es la que suscita mayor consenso entre historiadores y antropólogos que estudian esta área.

3 Según Febrés (1764:490) “Ghùlmen- Cazique, y hombre rico y de respeto". Aquí se usa cacique y ulmen porque los documentos hispanocriollos refieren a ambos, probablemente destacando la diferencia entre los caciques gobernadores que reciben bastón, nombrados huinca ghùlmen según Febrés, y aquellos que tienen autoridad entre los indígenas aunque no tengan bastón o mapughùlmen.

4 Fr. Francisco Xavier de Alday en carta enviada al Sr. Gobernador Alexandro Eagar en 1807, AFCCh. Vol. 10 fojas 48 a 55 vta. La cita indica que: "En el día han desaparecido todos estos indios que podian componer la Misión, ó agregándose á la clase de los Españoles ó muriendo con las repetidas pestes.... esta de manifiesto que todos los terrenos que ocupaban estos Indios, son hoy posesion de españoles, ó por herencia, ó por compra á los que fueron sus legitimos dueños.”. El destacado es mío.

5 Valdivia estuvo sujeta a cambios durante el período considerado en la investigación (aproximadamente 1770 a 1848); los límites espaciales del antiguo Gobierno y luego Provincia de Valdivia estaban, al norte en el río Toltén, fijándose a principios del siglo XIX en el río Cautín o Imperial; el límite sur fue por mucho tiempo el río Bueno y a partir de 1796 el río Maipué; el límite oeste el mar, y el este, la cordillera nevada. En 1797 Osorno pasó a depender del virreinato, hasta que en 1802 se reintegró, volviendo el límite sur al río Maipué. En 1826 se decretó una nueva división administrativa en la que se ratificó la antigua jurisdicción de Valdivia entre el río Toltén y el Maipué pero bajo el nombre de provincia. Finalmente, en 1861, cuando se formó la provincia de Llanquihue, el departamento de Osorno dejó de pertenecer a la provincia de Valdivia.

6 En Petrucci, 2002:9: "Según Giorgio Raimondo Cardona, historiador de las escrituras y de las lenguas, 'la escritura puede ser todo lo que nosotros logremos leer en ella': ante todo, lo que concierne a los hombres que la han usado y su mundo". 
A través del análisis de un conjunto de cartas escritas por caciques y ulmenes mapuche-huilliches a autoridades de Valdivia, en el período colonial tardío, es posible aprehender el significado otorgado a la escritura y el uso que se le dio en la interacción entre mapuchehuilliches e hispanos en Valdivia. Como ha señalado Petrucci, la apropiación de la escritura no dependió de la existencia de una sociedad altamente alfabetizada, por el contrario, una de sus expresiones más frecuentes en el contexto colonial "el fenómeno de la 'delegación de escritura' es antiguo y característico de sociedades parcialmente alfabetizadas en las que, sin embargo, las estructuras públicas, estatales o municipales, fuertemente burocratizadas exigen de los ciudadanos o súbditos, en vista de finalidades fiscales, administrativas, judiciales, declaraciones autógrafas o suscripción autógrafa" (Petrucci, 2002: 30).

Los escritos analizados corresponden a aquellos generados como parte de interminables procesos de negociación a los que se vieron expuestas las colectividades indígenas. Para Lienhard, estos textos "escritos, dictados o dichos" por indios forman parte de una textualidad indígena, pero no son "literatura indígena"; según este autor, estas colectividades crean un discurso distinto, capaz de llegar a los extraños, adversarios o posibles aliados; estos discursos destinados a los extraños se inscriben en una relación conflictiva entre colonizado y colonizador, desarrollando un diálogo intercultural que mostraría un enfrentamiento entre la cultura impuesta y la propia, fundamental para conocer los procesos de interacción cultural entre indígenas e hispanos (1992:XII-XIII).

Estas cartas y los indicios encontrados en diversos documentos administrativos y misionales muestran que la práctica de escribir peticiones era bastante frecuente para un sector de la sociedad mapuche-huilliche en la segunda mitad del siglo XVIII. La apropiación y valoración de la escritura se relaciona con tempranos e incuestionables trasvases de individuos e información entre el mundo español y el indígena.

Carlos Lázaro ve el respeto de los mapuches a la legalidad escrita como un ejemplo, aunque marginal, del uso generalizado que hicieron otros indígenas sometidos al gobierno colonial de los mecanismos jurídicos que la Corona les concedía. Este autor llama la atención sobre el siguiente texto de Rosales que destaca el papel de los cautivos en la difusión de estas prácticas en el siglo XVII:

"de tal suerte que los indios de Osorno y Cunco que son fronterizos de los españoles de Chiloé, viendo que ni juramento ni palabra real se les cumplía, y que si daban la paz luego les maloqueaban con cualquier pretexto, tomaron como medio pedir el sello real, porque algunos cautivos españoles les habían dicho el respeto que se tenía al sello real" (2002:228).

En este contexto, la temprana valoración de la escritura fue resultado de la comprensión de un segmento de la sociedad mapuche-huilliche de la existencia de un marco jurídico-administrativo colonial al que podía acceder para asegurar cierto respeto a los acuerdos. Para estos fines, la alfabetización de los caciques no era esencial, las prácticas de delegación de escritura funcionaron con bastante éxito hasta avanzado el siglo XIX.

La difusión de la escritura se amplió con el envío de hijos de autoridades mapuchehuilliches a estudiar, una práctica presente en Valdivia desde su refundación, a mediados del siglo XVII. Desde la perspectiva indígena la decisión de alejar temporalmente a los jóvenes para enviarlos a estudiar no debió estar exenta de desacuerdos e incertidumbre ${ }^{7}$, pero probablemente fue visualizada como una estrategia que permitiría controlar, intervenir y fiscalizar los tratos con los hispanocriollos. Existen antecedentes que revelan que hubo un flujo conti-

7 Un antecedente que muestra la resistencia de los mapuche-huilliches a alejar sus hijos de las parcialidades en la segunda mitad del siglo XVIII es entregado por Fr. Pedro Valcárcel, misionero de la Mariquina, quien, frente a la idea del Gobernador Joaquín Espinoza para que envíe algunos niños de su misión a estudiar en Valdivia, propone que se apoye el establecimiento de una escuela en la misión, contesta que no ve posible enviarlos a Valdivia “...practicaré las diligencias Correspondientes para el Establecimiento de Esquela en esta Mission instando á sus Indios para que me entreguen sus hijos. En la inteligencia, de que los dichos, ni los querrán dar, ni yo pienso pedirselos para otra parte; porque de qualquier resulta adversa que tuviesse alguno, aunque fuesse Cassual; para con ellos serian Responsables los Missioneros, y seria esto Suficiente Motivo para mirarlos con desafecto, y no entregar en lo de adelante sus hijos". AFCCh, Vol. 3. 
nuo, aunque muy selectivo, de hijos de caciques que salieron de sus tierras a educarse en Valdivia, Concepción y posteriormente Chillán. Guarda (1976) indica que varios jóvenes huilliches estudiaron bajo la tutela de gobernadores de la ciudad y destaca los casos de los "caciques gobernadores de Toltén" Martín de las Cuevas y Francisco de las Cuevas y Quilacán, descendientes de un español cautivado después de la destrucción de Valdivia, quienes recibieron educación en colegios jesuitas (Guarda, 1968). Finalmente, los archivos del Colegio de misioneros franciscanos de Chillán, muestran que en las últimas décadas del siglo XVIII hubo un grupo de hijos de caciques huilliches de Cudico, Dallipulli, Río Bueno y Rahue que estudiaron en el Seminario de Naturales de Chillán, continuando algunos sus estudios en Santiago.

Las cartas de los "ulmenes" mapuche-huilliches

Estos procesos de apropiación de la escritura se evidencian en la circulación de un conjunto de cartas enviadas a distintas autoridades hispanocriollas por caciques y "ulmenes" mapuche-huilliches de la jurisdicción de Valdivia. Las cartas están fechadas entre 1766 y 1808 y junto a ellas se incluyó dos documentos que refieren a escritos enviados, uno por el cacique Manuel Queipul en 1809 y otro por indígenas de Niebla, en 1815. A continuación se muestra un cuadro resumen (en página siguiente).

En su estructura formal estas comunicaciones son "peticiones", esto es, "demandas por un favor, o por compensación de una injusticia, dirigidas a alguna autoridad" (Van Voss, 2001:1). Para Van Voss, estas peticiones son posibles cuando "se considera que la distribución de justicia y la generosidad forman parte importante de gobernar, por lo tanto, los que gobiernan difícilmente pueden negar a sus gobernados el derecho de acercarse e implorarles que ejerzan justicia o les otorguen un favor"8 (2001:1). El carácter de estas peticiones dependía del contexto de su presentación, si eran individuales o grupales, el tipo de autoridad a la que se dirigían y las prescripciones para su presentación, pero siempre se escribían en un tono respetuoso que mostraba que el "suplicante" no intentaba cuestionar la estructura de poder establecida, lo que según el autor tendría sentido porque las peticiones eran dirigidas, usualmente, a los niveles más altos de esta estructura de poder.

La comprensión de las peticiones huilliches debe considerar las características de esta área, denominada en ocasiones la "frontera de arriba" (Urbina, 2005) y las transformaciones profundas generadas a partir de 1750 , por el aumento progresivo del contacto hispano-indígena hacia el sur del río CalleCalle. Las peticiones fueron escritas en el período de expansión de la Plaza de Valdivia, que transcurrió entre 1750 y 1820 (Vergara, 2005) en el que se concretó el sometimiento de los huilliches (después del levantamiento de 1792) y la incorporación a la Corona del territorio situado al sur del río Bueno.

El establecimiento de fuertes, misiones y colonos españoles en el territorio indígena tuvo como consecuencia la instauración de un nuevo orden de relaciones con los mapuchehuilliches que es representado en el conjunto de documentos que provienen de "reducciones" donde había misiones y funcionarios de indios. Las cartas muestran los vínculos generados por huilliches con funcionarios de indios y comerciantes, quienes inscribían en papel estas peticiones, ya por sus lazos de parentesco, ya a cambio de productos de "la tierra". Estos documentos también representan las tensiones generadas por esta expansión, mostrando las estrategias mapuche-huilliches para resistir y adaptarse a este nuevo orden, destacando en ellos las negociaciones destinadas a neutralizar la acción de los misioneros. Por otro lado, un elemento clave representado en estas peticiones, se relaciona con un hecho muchas veces ignorado al examinar las relaciones interétnicas hispanomapuches, a saber, que la categoría "españoles" rara vez funcionó como un todo integrado. Las cartas muestran las tensiones entre diferentes agentes estatales: autoridades misionales que reclaman contra el gobernador de la Plaza, a favor o en contra de los huilliches; misioneros que

8 En mi traducción, el original dice: "Petitions are demands for a favour, or for the redressing of an injustice, directed to some established authority. As the distribution of justice and largesse are important parts of ruling, rulers can hardly deny their subjects the right to approach them to implore them to exercise justice, or to grant a favour". 
Listado cronológico de las cartas analizadas

\begin{tabular}{|c|c|c|c|c|c|}
\hline FECHA & UBICACIÓN & EMISOR & DESTINATARIO & $\begin{array}{l}\text { ÁREA DE } \\
\text { PROCEDEN- } \\
\text { CIA EMISOR }\end{array}$ & MOTIVOS/CONTENIDOS \\
\hline 1766 & $\begin{array}{l}\text { A.N. Capitanía } \\
\text { General Vol. } \\
537 \text { fojas } 211 \\
\text { vta. a } 213 .\end{array}$ & $\begin{array}{l}\text { Manuel de las Cuevas Culacan } \\
\text { "gobernador de mi juris- } \\
\text { dicción de Toltén" con su } \\
\text { "capitanejo" y "caciques" de } \\
\text { su parcialidad" }\end{array}$ & $\begin{array}{l}\text { Gobernador de } \\
\text { Valdivia Félix } \\
\text { de Berroeta }\end{array}$ & $\begin{array}{l}\text { Jurisdic- } \\
\text { ción de } \\
\text { Toltén }\end{array}$ & $\begin{array}{l}\text { Solicitan se instale misión } \\
\text { en sus tierras. }\end{array}$ \\
\hline 1789 & $\begin{array}{l}\text { A.N. Capitanía } \\
\text { General, Vol. } \\
\text { 315. f. } 164 .\end{array}$ & $\begin{array}{l}\text { "Caciques embajadores" } \\
\text { Trangol, Queipul y Catriguala }\end{array}$ & $\begin{array}{l}\text { Gobernador de } \\
\text { Valdivia Maria- } \\
\text { no de Pusterla }\end{array}$ & $\begin{array}{l}\text { Jurisdic- } \\
\text { ción de Río } \\
\text { Bueno y } \\
\text { Rahue }\end{array}$ & $\begin{array}{l}\text { Piden se libere de prisión } \\
\text { al soldado Mariano Arango } \\
\text { de Valdivia "pariente muy } \\
\text { cercano" de Trangol. }\end{array}$ \\
\hline 1796 & $\begin{array}{l}\text { En Guarda, } \\
\text { 2000:17, } \\
\text { refiere a CM } \\
4728 .\end{array}$ & $\begin{array}{l}\text { “Cacique principal” Tomás } \\
\text { Theca Ñancu (primero en } \\
\text { hablar en los parlamentos) }\end{array}$ & $\begin{array}{l}\text { Gobernador de } \\
\text { Valdivia Juan } \\
\text { Clarke }\end{array}$ & $\begin{array}{l}\text { Reducción } \\
\text { de San } \\
\text { José de la } \\
\text { Mariquina }\end{array}$ & $\begin{array}{l}\text { Por su pobreza, pide se le } \\
\text { asigne sueldo "a similitud } \\
\text { de los que gozan los caci- } \\
\text { ques del sur" }\end{array}$ \\
\hline 1803 & $\begin{array}{l}\text { A.N. Archivo } \\
\text { Judicial de } \\
\text { Valdivia, leg. } 4\end{array}$ & $\begin{array}{l}\text { Cacique de Dallipulli “Ber- } \\
\text { nardo Callvugùru” (Calfun- } \\
\text { guir o Calvugur) }\end{array}$ & $\begin{array}{l}\text { Gobernador de } \\
\text { Valdivia Juan } \\
\text { Clarke }\end{array}$ & $\begin{array}{l}\text { Reducción } \\
\text { de Dalli- } \\
\text { pulli }\end{array}$ & $\begin{array}{l}\text { Da gracias al gobernador } \\
\text { por intervenir con justicia } \\
\text { en pleito por tierras y pide } \\
\text { aclare una cláusula escrita } \\
\text { en la escritura. }\end{array}$ \\
\hline 1805 & $\begin{array}{l}\text { Archivo Fran- } \\
\text { ciscano Cole- } \\
\text { gio de Chillán } \\
\text { (AFCCh) Vol. } \\
10, \text { fs. } 237 \text { y } \\
238 .\end{array}$ & $\begin{array}{l}\text { Francisco Callimanque } \\
\text { "Capitanejo con función de } \\
\text { cacique", Arique }\end{array}$ & $\begin{array}{l}\text { R.P. Padre } \\
\text { Presidente ¿F. } \\
\text { J. Alday? }\end{array}$ & $\begin{array}{l}\text { Reducción } \\
\text { de Arique }\end{array}$ & $\begin{array}{l}\text { Quejas sobre maltra- } \\
\text { tos del misionero y por } \\
\text { quitarle "una sobrina a su } \\
\text { servicio". }\end{array}$ \\
\hline 1806 & $\begin{array}{l}\text { AFCCh, Vol. } 10 \\
\text { fs. } 98 \text { a } 102\end{array}$ & $\begin{array}{l}\text { "Gilmen" Chanquen de } \\
\text { Quechupulli }\end{array}$ & $\begin{array}{l}\text { Gobernador de } \\
\text { Valdivia Juan } \\
\text { Clarke }\end{array}$ & $\begin{array}{l}\text { Reducción } \\
\text { de San } \\
\text { José de la } \\
\text { Mariquina }\end{array}$ & $\begin{array}{l}\text { Queja contra los misione- } \\
\text { ros por apropiarse de un } \\
\text { terreno que le pertenece }\end{array}$ \\
\hline 1808 & $\begin{array}{l}\text { A.N. Capitanía } \\
\text { General, Vol. } \\
508 \text { f. } 247 .\end{array}$ & $\begin{array}{l}\text { "Cacique" de Cudico San- } \\
\text { tiago Aucaguer y "Guilmen" } \\
\text { Guichulef }\end{array}$ & $\begin{array}{l}\text { Gobernador } \\
\text { Alejandro } \\
\text { Eagar }\end{array}$ & $\begin{array}{l}\text { Reducción } \\
\text { de Cudico }\end{array}$ & $\begin{array}{l}\text { Reclaman por sueldos que } \\
\text { se les adeudan (Cacique y } \\
\text { balsero del Pilmaiquen). }\end{array}$ \\
\hline 1809 & $\begin{array}{l}\text { AFCCh Vol. } 12 \\
\text { fojas } 11 \text { y } 12\end{array}$ & $\begin{array}{l}\text { "Cacique" Queipul "el nuevo } \\
\text { Queipul” }\end{array}$ & $\begin{array}{l}\text { Gobernador } \\
\text { Alejandro } \\
\text { Eagar }\end{array}$ & Río Bueno & $\begin{array}{l}\text { No está la carta, sino } \\
\text { la representación del } \\
\text { gobernador al Presidente } \\
\text { de misiones, sobre haber } \\
\text { recibido quejas por escrito } \\
\text { contra el P. Balzategui; en } \\
\text { otro documento de } 1807 \\
\text { hay antecedente de quejas } \\
\text { del cacique en una visita } \\
\text { general a la Plaza, contra } \\
\text { el mismo misionero. }\end{array}$ \\
\hline 1815 & $\begin{array}{l}\text { AFCCh, Vol. } 14 \\
\text { foja } 3\end{array}$ & $\begin{array}{l}\text { "Indios de la Costa de Nie- } \\
\text { bla” Manuel Loncomilla y An- } \\
\text { tonio Millanco (Millañamcu) }\end{array}$ & $\begin{array}{l}\text { Gobernador } \\
\text { Francisco } \\
\text { Arenas }\end{array}$ & $\begin{array}{l}\text { Costa de } \\
\text { Niebla, } \\
\text { naturales } \\
\text { de Isla del } \\
\text { Rey }\end{array}$ & $\begin{array}{l}\text { Queja por haber, los pa- } \\
\text { dres misioneros, azotado } \\
\text { y retenido en su poder a } \\
\text { sus hijas “por haber parido } \\
\text { solteras". No está la carta } \\
\text { sino la representación del } \\
\text { gobernador de haberla } \\
\text { recibido. }\end{array}$ \\
\hline
\end{tabular}

9 Para describir el emisor usé la denominación que aparece en los documentos y conservé la ortografía. 
acusan a funcionarios de indios de no cumplir con sus deberes, misioneros y militares que se disputan el derecho de decidir qué autoridad religiosa tiene jurisdicción sobre empleados indígenas, etc.

El panorama evidenciado en las peticiones no coincide con la imagen de la Plaza y Presidio de Valdivia que describe el historiador colonial valdiviano Martínez de Bernabé en 1782. Este presenta un territorio con límites fijos "rodeado de indios desde las fronteras de la Concepción de Chile hasta Chiloé" donde el espacio poblado por españoles alcanzaba hasta el puerto de Cruces "siete leguas de la ciudad río arriba [Río Cruces] que es frontera de indios, con algunos vecinos $i$ los que hai esparcidos hasta diez o doce leguas de distancia”. Hacia el sur, sigue Martínez de Bernabé, estaba el fuerte de Río Bueno con su guarnición y las "ocho misiones ${ }^{10}$ y reducciones de indios, los soldados que se ocupan de capitanes $i$ tenientes de amigos i son como espías de sus intentos" todo lo demás "es poseido i habitado de estos naturales" (1898: 97). El énfasis del cronista en el aislamiento de la Plaza y su representación de una inquietante "frontera de indios", contrasta con el espacio más bien abierto y fluido que transmiten las cartas; una zona de múltiples contactos y redes entre españoles, mestizos y huilliches y de una interacción estrecha y continua reflejada en las alianzas entre caciques y funcionarios de indios y en la integración entre los vecinos de Valdivia de mestizos, que viven evidentemente entre dos mundos. Examino a continuación algunos indicios de estas redes que se tejen en Valdivia.

Parte de esta trama de relaciones son representadas en la siguiente carta escrita en la misma década que el texto de Martínez de Bernabé, por los conocidos caciques Queipul, Trangol y Catriguala; transcribo unos párrafos:

\section{"SEÑOR GOVERNADOR}

Los Caciques que en calidad de embaxadores han venido á esta Plaza de la otra vanda de las Misiones de Río-Bueno, nombrados Tràngòlo, Quèypùl, y Catriguàla de los Llanos que cahen acia la parte de la Ciudad de Osorno; con el devido acatamiento que deven ante vs. paresen, y dicen: Que ha llegado a su noticia hallarse preso en la carzel de èsta Plaza el Soldado Mariano Arango à mas tiempo de tres años, (Pariente muy cercano del primero) por la muerte que dio a Miguel Coronao, en circunstancias de haverse visto obligado a ponerse en defenza de su vida por la furia con que el finado le acometía, y queria abasallar, dandole desmedidos golpes, como mas largamente consta de la sumaria que de sus resultas se formó contra el citado Mariano, à que se refieren".

Después de explicar que el proceso ha demorado más de la cuenta, por estar probablemente extraviado en la Capitanía General, e indicar los padecimientos que está sufriendo "este pariente", finalizan su carta señalando que:

"Por todo ello se ven obligados los exponentes (condolidos con estos padecimientos) a poner en la alta penetracion de vs. y pedirle por el expresado Mariano, se digne con su àcostumbrada, acreditada Caridad, mirarlo con la piedad posible, como Padre y Bienhechor que de estos distritos, y darle soltura de la dilatada prision que tolera; o quando lugar no haya, se sirba asignarle algun moderado extrañamiento de esta Plaza y presidio: Por todo lo que=

A VS. pedimos, y suplicamos se sirva mandar hacer en todo según y como llebamos pedido, que sera merced con gracia que esperamos alcanzar de la acostumbrada caridad y benignidad de vs.

\section{El Cazique Trangol \\ El Casique Queypul \\ El Casique Catriguala"11.}

En sus aspectos formales, al igual que la mayoría de las cartas analizadas, se trata

10 Estas ocho misiones eran la de Valdivia, San José de la Mariquina, Toltén, Costa de Niebla, Arique, Cayumapu, Quinchilca y Río Bueno.

11 Capitanía General, Vol. 315. f. 164. Se extendieron las abreviaturas, pero se conservó la ortografía. Las firmas están en el original en el orden en se presentan, el vocablo "cacique" está escrito con ortografía diferente. 
de una petición sobre un motivo particular que afecta a un individuo y que no envuelve al colectivo que estos "caciques embaxadores" están representando en Valdivia.

¿Por qué Trangol, Queipul y Catriguala se presentan como "caciques en calidad de embaxadores"? Si ponemos atención la carta está fechada en Valdivia, el 26 de febrero de 1789 , es decir, un día después de concluir el Parlamento que confirmó acuerdos con agrupaciones huilliches para abrir el camino a Chiloé y que el gobernador Pusterla aprovechó para 'amistar' a agrupaciones huilliches consideradas hasta entonces en continuo conflicto $^{12}$. Como se dijo anteriormente, la expansión valdiviana y estas intervenciones en las dinámicas internas huilliches se venían produciendo desde mediados de siglo XVIII, pero se incrementaron cuando la sociedad huilliche, debilitada por las luchas entre agrupaciones zonales y la disminución del ganado, se abrió a negociar con los valdivianos para obtener apoyo y defensa contra los ataques de otras agrupaciones zonales (Alcamán, 1997). Las relaciones de Queipul y Trangol con la Plaza se remontaban a la década de 1770; en 1777 Queipul aparece como cacique amigo en la expedición en busca de los Césares (Delgado, 1995) y, aunque entre 1782 y octubre de 1783 estuvo detenido en Santiago, por su supuesta participación en un levantamiento junto con los caciques Loncochino y Guecha$\tilde{\text { ñir }}{ }^{13}$, al volver a sus tierras el cacique continuó su relación con la Plaza de Valdivia. De este modo, la presencia de estos caciques en Valdivia, con la excepción de Catriguala, no era una novedad. Por otro lado, la petición fue enviada en un momento propicio, pues el Gobernador estaba dispuesto a interceder (como efectivamente lo hizo) para asegurar la voluntad de los caciques para la apertura del camino a Chiloé.

Como se desprende del párrafo anterior, la autonomía huilliche que duró hasta fines del siglo XVIII, se dio en un contexto de articulación de ambas sociedades y múltiples mecanismos de comunicación, alianzas y contactos en los que participaron diversos mediadores culturales entre los que se encontraban los lenguaraces, funcionarios de indios, comerciantes, caciques, soldados españoles y huilliches y trabajadores agrícolas y domésticos, entre otros. El parentesco del soldado Mariano Arango con el cacique Trangol es un ejemplo de estos mecanismos de alianza que conectaban individuos de agrupaciones independientes y aquellos que vivían en la Plaza de Valdivia. Aunque el vínculo de Arango con Trangol no se explicita en el expediente, probablemente correspondió a uno de los frecuentes matrimonios entre mujeres indígenas (de diversos puntos del territorio: “infiel" y "cristianizado") y soldados de Valdivia, uniones atestiguadas por informes de misioneros ${ }^{14}$. Por otro lado, la representación de parlamentos y las visitas, muestra que estos acontecimientos tuvieron múltiples dimensiones que fueron más allá del establecimiento y confirmación de vínculos entre las autoridades de ambas sociedades. Los parlamentos eran el momento propicio para establecer una serie de lazos comerciales, intercambiar productos y actualizar relaciones entre parientes y aliados, como se observa en el relato del padre

12 “En cumplimiento de las instrucciones..." Valdivia, marzo de 1789 AGI Chile 221. Cf. Urbina, 1988. En este parlamento el gobernador de Valdivia instó a agrupaciones huilliches enemistadas a entablar relaciones pacíficas; por un lado, estaban el cacique Gobernador de los Llanos Carfunguir de Dallipulli, y los caciques Rumillanca de Catalan, Colin y Guayquipan de Quilacaguin y sus ulmenes, y por el otro, los caciques Queypul, Tangol, Catriguala, Dunguigual y sus ulmenes. Hablaron los caciques gobernadores Carfunguir y Queypul, cada uno en nombre de su parcialidad, y dijeron que "estaban prontos a hacer las amistades en presencia de su Señoría: Les dio el Señor Governador las gracias, y les hizo presente la cesion que havia echo del camino y lo que cada parcialidad havia ofrecido en la Junta celebrada en Quilacaguin y Raugue...”, posteriormente, "Dieron las gracias a su Señoría y el Cazique Governador Carfunguir hablo a el Cazique Queypul, y consecutibamente los caziques, y Guilmenes de una y otra Parcialidad se abrazaron, y dieron las manos Brindandose segun sus ritos, para lo que les fue dado por el Señor Governador dos Banderas Blancas una a los caziques Colin y Guayquipan y otra al Cazique Catriguala, que aun no la tenian como los demas amistados las tenian en señal de la Paz y Alianza con la Plaza, cuya bandera trocaron las parcialidades una con otra en señal de amistad; despues de muchos razonamientos de unos á otros. Les dijo el Señor Governador que en virtud de ser ya todos unos havian de conservar la Paz y Tranquilidad del transito por el nuebo camino...".

13 Capitanía General vol. 665 fojas 118-172. Loncochino murió en el Hospital San Juan de Dios , “de pujos”.

14 Los documentos del archivo del Colegio de Misiones de Chillán entregan muchas pistas sobre estas uniones, sobre todo cuando los misioneros se refieren a las "transmigraciones" de indígenas bautizados o casados a tierras de infieles y cuando disputan la "jurisdicción espiritual” sobre los indígenas que viven en la Plaza. 
Valcárcel sobre la visita de los caciques de Mariquina. Esta descripción los muestra en su viaje a Valdivia, acompañados del Lengua General ("funcionario de indios") a "decirle [al gobernador] que no ai novedad en sus tierras" y a tratar sus propios "negocios" como componer hachas, frenos y mariscar ${ }^{15}$.

La mediación de "funcionarios de indios" y caciques de diferentes áreas de la jurisdicción fue central en la articulación de ambas sociedades. La carta enviada por el "Gilmen Chanquen de Quechupulli" al gobernador Juan Clarke, solicitando se haga justicia por un terreno que le quieren quitar los misioneros, ejemplifica estas relaciones. La carta está firmada por Bernardo Montesinos, Lengua General de Valdivia, quien deslindó el terreno. Este "funcionario de indios" tenía estrechas relaciones con los caciques del área norte de Valdivia; pero su relación con ellos no se limitaba a su participación en el sistema de mediación de la Corona con los indígenas. Un interrogatorio sobre la queja de los misioneros franciscanos por la destrucción del cementerio indígena de la Misión ${ }^{16}$, nos muestra sus vínculos de parentesco con aquellos caciques, además de resaltar lo difusos que podían resultar los límites étnicos en esta zona de frontera. "Don Bernardo Montesinos" se define como nacido en la Plaza de Valdivia, pero nieto de los caciques de Donguil; afirma hablar la lengua mapuche perfectamente "porque es su lengua natural", pero también porque su trabajo lo hace recorrer la tierra, arreglando sus "pleytos y quimeras", agregando que por ser "muchos los Indios Caciques parientes suyos, conoce perfectamente el genio dellos, sus ritos y sus costumbres". Montesinos está entre dos mundos, la lengua de los caciques es su lengua natural por ser su nieto, pero habla de sus "ritos" y sus "abusos" (de ellos) interponiendo distancia y validando su papel de funcionario de la Corona. Su papel de mediador político y cultural, probablemente fue facilitado por su parentesco biológico, pues hay abundantes ejemplos de "funcio- narios de indios" mestizos. Sin embargo, los vínculos biológicos no fueron condición para establecer redes y alianzas con los ulmenes; donde no existían vínculos de consanguinidad o afinidad, los funcionarios de indios y otros militares apreciados por los caciques, fueron integrados como parientes. Los casos de Francisco Aburto y Teodoro Negrón son ilustrativos. Negrón indica que no tiene parentesco 'con cacique indio alguno, pero que algunos lo llaman pariente en señal de amistad o aprecio'. A Francisco Aburto, el cacique de Boroa lo llama pariente, lo que, según dice, "admite por amistad" 17.

Acorde con estas dinámicas, la lengua mapuche era hablada no solo por los funcionarios de indios, comerciantes y militares que se internaban tierra adentro; su uso se extendía a los vecinos de la Plaza, como se deduce de una carta enviada en 1774 por Fr. Joaquín Millán al Gobernador de Valdivia, Joaquín Espinoza, en la que señala que la mayoría de los indígenas que viven en Valdivia no hablan "el idioma castellano" y no necesitan hablarlo porque los españoles nacidos y criados en Valdivia "hablan la lengua índica a la perfección y se dirigen a ellos en esta lengua"18.

Finalmente, uno de los aspectos más interesantes representados en estos documentos dice relación con las complejas interacciones entre los caciques y "ulmenes" mapuche-huilliches, los misioneros y los gobernadores de la Plaza de Valdivia. Como mencioné anteriormente, en este período se produjo la expansión de las misiones; los misioneros franciscanos que reemplazaron 1769 a los padres jesuitas y trabajaron en estrecha colaboración con las autoridades de Valdivia, aunque con evidentes tensiones y luchas internas. El resultado fue el rápido establecimiento de misiones en las que aplicaron una metodología diferente a la de los anteriores misioneros, intentando imponer un mayor control sobre las "reducciones" o conjuntos de parcialidades que incluían dentro de su espacio misional, que redujeron para

15 Comunicaciones entre Fr. Pedro Valcárcel, misionero de San José de la Mariquina, y el Gobernador Espinoza sobre las quejas de los caciques de Mariquina por el trato del Gobernador, fechadas en 3 y 4 de enero de 1775. AFCCh, vol. 3, fojas 151 a 153.

16 AFCCh Vol. 10 fojas 98 a 102.

17 Ibídem.

18 AFCCh, vol. 3 fechada en 29 de diciembre de 1774. 
lograr sus propósitos ${ }^{19}$. Frente a la imposibilidad de congregar a los mapuche-huilliches en pueblos, optaron por trasladarlos a la misión en grupos de número variable y por períodos cortos (Poblete, 2005).

El asentamiento de misiones en el territorio mapuche-huilliche, indudablemente significó un cambio en su relación con el mundo hispano; hizo más accesibles recursos económicos por la vía de diversas gratificaciones y en ocasiones propició la defensa de las fuerzas hispanas en situaciones de conflicto intraétnico. No obstante, la misión franciscana ejerció una presión para convertirlos y civilizarlos, que probablemente no fue calculada por los caciques y dividió a los grupos entre quienes privilegiaban las alianzas con los misioneros y los que se vincularon con otros funcionarios coloniales. Las estrategias huilliches variaron espacial y temporalmente frente la coacción que ejercieron los misioneros para moldear a sus "neófitos" según las normas del cristianismo. Algunos "ulmenes" se convirtieron y participaron junto a sus agrupaciones de la enseñanza de la doctrina y el cumplimiento de los sacramentos. Fue frecuente que los caciques se mantuvieran "infieles", negándose a recibir el bautismo y a enterrarse en cementerios misionales, aunque favorecieran el cumplimiento de los sacramentos de su parentela. En otros casos, los "ulmenes" resistieron la acción misional, enfrentando a los misioneros y relacionándose con otros agentes estatales para balancear esta situación. Sin embargo, unos y otros se mantuvieron apegados a aquellas costumbres que los misioneros buscaban erradicar: la poligamia, los entierros según "sus ritos", el tratamiento de enfermedades por medio de machis, etc. Las tensiones producidas por el asentamiento de las misiones se reflejan en las peticiones, en las que se ve el uso de los documentos escritos por parte de los mapuche-huilliches que se oponían a las prácticas que intentaban imponer los misioneros.

La siguiente petición nos remite a la "reducción" de Arique, ubicada al este de Val- divia siguiendo el curso del río Calle-Calle, en la que se establecieron los misioneros franciscanos en 1774. Quien la envía es "Francisco Callimanque, Indio Christiano, Capitanejo con función de Casique de la Reducción de Arique". La presentación es una queja contra el misionero Fr. Juan Ferretjans, a quien el autor denomina "Juan Curiñancu"; Callimanque lo acusa de quitarle una sobrina, porque estaba embarazada, llevándola a servir en la Misión. Además de esta queja particular, el capitanejo realiza una acusación general en contra del misionero y pide que se amoneste a "nuestro dicho patiru, pues es muy enojon a los indios los trata a puñetes, patadas y agarrarlos de los cabellos. De manera que su impertinencia le ha hecho odioso que el Pueblo me ha pedido que le haga presente..." ${ }^{20}$. Esta carta escrita en 1805 , contiene una queja similar a la que describe en 1815 el Gobernador Francisco Arenas, en la que los "Indios de la Costa de Niebla Manuel Loncomilla y Antonio Millanco"21 se quejan contra los misioneros de la Misión de la Costa de Niebla porque azotaron y retuvieron en su poder a sus hijas "por haber parido solteras". Estas cartas muestran las presiones ejercidas por algunos misioneros, la mirada indígena a los medios para civilizar y cristianizar a los indígenas y sus estrategias para neutralizar estas prácticas. Quienes enviaron estas peticiones, estaban al tanto de las vías para conseguir la escritura de la petición a través del intercambio de bienes de su producción cotizados por los valdivianos, "un chancho flaco" y pescado. Además, conocían las formas de llegar a las autoridades de Valdivia para que fueran consideradas. El resultado de ellas es dispar; mientras en la primera el gobernador recomienda un castigo para quien hizo el escrito y no se refiere al fondo de la queja; en la segunda, enviada casi al final del período español en Valdivia, el gobernador recomienda a los religiosos que examinen el punto "a fin de que se corten resentimientos de esta especie que puedan hacer odiosas a las comberciones y embolberlas en otras consecuencias más sensibles"22.

19 Los propósitos de controlar esta población, de contabilizarlos, bautizarlos y vigilarlos, nos remiten a la interpretación que hace Boccara (1998 a y b) de la misión y la escuela como instituciones de vigilancia y disciplinamiento de los mapuches. Sin embargo, esta interpretación olvida incorporar la resistencia, apropiación y resignificación de estos procesos.

20 AFCCh, vol. 10, fojas 237 y 238.

21 AFCCh, vol. 14 foja 3.

22 AFCCh, vol. 14, fojas 10 y vta. 
Las cartas también representan las luchas entre los misioneros y las autoridades de la Plaza. Misioneros y autoridades colaboraron en el establecimiento de misiones, no obstante, su organización y funcionamiento cotidiano provocó frecuentes enfrentamientos. Los religiosos criticaban el papel asignado a los caciques gobernadores y los privilegios que les otorgaban los gobernadores de Valdivia; entre los puntos más criticados por los misioneros estuvo la negativa a forzar a los indígenas a cristianizarse o a mantenerse en los territorios "cristianizados", que parece hacerse común al terminar el siglo XVIII ${ }^{23}$. Los gobernadores de Valdivia sostuvieron que era labor de los misioneros atraer "por medios suaves" a los bautizados para que permanecieran cerca de las misiones. Haciendo uso de estos antagonismos, un segmento de los huilliches logró sortear muchas veces con éxito las obligaciones que quisieron imponer los religiosos. La reacción de los misioneros frente a las quejas presentadas por el cacique Manuel Queipul de Río Bueno grafican estas dinámicas. Se sabe de esta carta por un documento enviado por Fr. Francisco Pérez, Prefecto de las Misiones de Valdivia al Guardián del Colegio de Chillán, Fr. Antonio Rocamora. En el escrito, fechado en Valdivia en marzo 15 de $1809^{24}$, Fr. Francisco Pérez informa al Guardián del Colegio de Chillán que el Gobernador Alejandro Eagar se ha quejado "de resultas de una carta de acusación, que mandó contra el P. Balzátegui su conocido Cazique el nuevo Queipul"25, el gobernador amenazó con enviar una queja a la Capitanía General, si no se sacaba al padre Balzátegui de la Misión de Río Bueno y se le enviaba al Colegio de Chillán. Esta respuesta del gobernador se entiende como parte de las estrategias de relación con los indígenas ensayadas por la Corona en el período colonial tardío; estas confiaron las relaciones con los "infieles" a los oficiales de gobierno e intentaron limitar a los misioneros al ámbito espiritual. Como ha sostenido Weber, "aunque los Borbo- nes reformistas y los misioneros compartían la meta de convertir a los indios en 'hombres racionales', los reformistas pensaban, más bien, en empezar por hacer a un indio un vasallo útil y un hombre sociable" antes de intentar volverlo un cristiano (Weber, 2005:104). En las últimas décadas del gobierno colonial, los gobernadores de Valdivia ejecutaron estas políticas esforzándose por mantener a los misioneros relegados a la evangelización de los indígenas y depositando en ellos la responsabilidad de conseguir estos fines sin "alborotar la tierra". Su forma de "civilizar" privilegió el establecimiento de lazos con los caciques gobernadores, por medio de las gratificaciones y de un trato preferencial y cercano. Es el tipo de relación que refleja la carta del gobernador Juan Clarke para que se aclare con prontitud un pleito por tierras que afecta al cacique de Dallipulli Bernardo Callvuguru y la respuesta de este ${ }^{26}$.

En síntesis, a través de estas peticiones los mapuche-huilliches negociaron y establecieron demandas, haciendo presente a las autoridades de Valdivia las injusticias cometidas por subordinados (los misioneros entre ellos), recordando también deberes del Estado, tales como el pago de sueldos y asignaciones. La mayoría de sus autores formaban parte de quienes se ha considerado parte de las élites indígenas, los denominados caciques gobernadores que estaban habilitados para negociar con el poder (cf. Lienhard 1992). Estas cartas o textos dirigidos a extraños por los mapuche-huilliches, no se circunscriben a los tiempos coloniales, excede los propósitos de este trabajo una comparación con escritos del período republicano pero hay antecedentes de que indican que en el siglo XIX los caciques presentaron "memoriales" al Presidente de la República que muestran cierta continuidad con estas $\operatorname{cartas}^{27}$. Finalmente, aunque con diferencias sustanciales, estas cartas anticipan la estrategia reivindicativa de los me-

23 Las presentaciones que hacen ante las autoridades de la Plaza piden ayuda para evitar las frecuentes "transmigraciones", el paso de los mapuche-huilliches bautizados, a tierras de "infieles" donde no cumplirán con los "deberes cristianos".

24 AFCCh, vol. 12 fojas 11 y 12.

25 Don Juan Queipul, el cacique que participó en el levantamiento de 1792, murió en 1803; este “Nuevo Queipul” debería ser Manuel Queipul, que es quien aparece en estas fechas en las transacciones de tierras. Ver archivos notariales y judiciales de Valdivia.

26 Archivo Nacional, Judicial Valdivia, leg. 4, fechada en 7 de junio de 1803.

27 Archivo Nacional, Ministerio del Interior, vol. 250 fojas 90 a 91v. "Memoria de la solicitud que hase el Casique Juan Felipe Bontequeo, al S Presidente de la Republica". 
moriales del siglo XX estudiados por Foerster y Vergara (2001), que fueron enviados por caciques huilliches a autoridades chilenas como parte de las luchas políticas de sus dirigentes y organizaciones.

\section{Bibliografía}

ALCAMÁN, E. (1997), Los Mapuche-huilliche del futahuillimapu septentrional: expansión colonial, guerras internas y alianzas políticas (17501792). Revista de Historia Indígena. 2: 29-76.

BARTH, F. (1976) (ed.), Los grupos étnicos y sus fronteras. FCE.

BOCCARA, G. (1998a), Dispositivos de poder en la sociedad colonial fronteriza chilena del siglo XVI al siglo XVIII. Pág. 29-41, en: Del Discurso Colonial al Proindigenismo. Ensayos de Historia Latinoamericana. Jorge Pinto R. (editor). Temuco: Ediciones Universidad de La Frontera.

BOCCARA, G. (1998b), Guerre et etnogenèse mapuche dans le Chili colonial. L'invention du soi. Francia: L'Harmattan.

COMAROFF, J., COMAROFF, J. (1992), Ethnography and the historical imagination. Boulder, Colorado: Westview.

DELGADO, B. O.F.M. (1995) (1778), Diario del R. P. Benito Delgado. Capellán de la expedición que se hizo para el descubrimiento de la Ciudad de los Césares. 1778 Publicaciones del Archivo Franciscano $N^{\circ} 44$. Santiago de Chile.

FEBRÉS, A. (1764), Arte de la lengua de Chile. Lima: Calle de la Encarnación.

FOERSTER, R., VERGARA, J.I. (2001), “Hasta cuando el mundo sea... los caciques huilliches en el siglo XX" en: Futawillimapu; Pilar Álvarez Santullano y Amilcar Forno Editores. Conadi. Programa Postítulo en EIB. Universidad de Los Lagos. 2001.

GUARDA, G. (1968), Los caciques gobernadores de Toltén en: Boletín de la Academia Chilena de Historia 78: 43-69.

GUARDA, G. (1976), La Cultura en Chile Austral antes de la Colonización Alemana.16451850. Valdivia: Universidad Austral de Chile.

GUARDA, G. (2000), Caciques y parlamentos, Valdivia-Osorno (1645-1820). Separata Boletín de la Academia Chilena de la Historia 108109: 13-29.

LÁZARO, C. (2002), El parlamentarismo fronterizo en la Araucanía y las Pampas. En: Boccara, G. (ed.) Colonización, resistencia y mestizaje en las Américas (siglos XVI-XX). IFEA- Lima. Quito: Ediciones Abya-Yala.

LIENHARD, M. (1992), Testimonios, cartas y manifiestos indígenas. (Desde la conquista hasta comienzos del siglo XX). Biblioteca Ayacucho.

MARTÍNEZ DE BERNABÉ, P. (1898), La Verdad en Campaña. Publicado por Nicolás Anrique en: Biblioteca Jeográfico-Hidrográfica de Chile. Segunda Serie. Santiago de Chile: Imprenta Elzeviriana.

MÉNDEZ, L. M. (1982), La organización de los Parlamentos de Indios en el siglo XVIII en: Villalobos, S. et al. 1982 Relaciones fronterizas en la Araucanía. Santiago: Ediciones Universidad Católica de Chile. Págs. 107 a 173.

PETRUCCI, A. (2002), La ciencia de la escritura. Primera lección de paleografía. Argentina: F.C.E.

POBLETE, M.P., (2005), Misiones franciscanas y educación indígena en Valdivia. 1769-1848. Ponencia presentada en el VI Congreso Internacional de Etnohistoria. Buenos Aires. Argentina. Noviembre de 2005.

URBINA, X. (2005), El territorio Junco-Huilliche como zona de frontera en los siglos XVII y XVIII. Ponencia presentada en las Jornadas de Historia de Chile. Osorno. 2005.

URBINA, R. (1988), Chiloé y la Ocupación de los llanos de Osorno durante el siglo XVIII. En: Boletín de la Academia Chilena de la Historia, 98 Santiago.

VAN VOSS, L. H. (2001), Introduction in: Van Voss, L. H. (editor) Petitions in social history. International Review of Social History 46 (2001) Supplement. Págs. 1-10.

VERGARA, J. I. (2005), La herencia colonial del Leviatán. El Estado y los mapuche-huilliches (1750-1881). Tesis de doctorado en sociología. Universidad Libre de Berlín.

VILLALOBOS, S. (1995), Vida Fronteriza en la Araucanía. El mito de la guerra de Arauco. Santiago: Editorial Andrés Bello. 
WEBER, D. (2005), Bárbaros. Spaniards and their savages in the age of enlightenment. New Haven and London: Yale University Press.

ZAVALA, J. M. (1998), L'envers de la Frontière du royaume du Chili. Le cas des traités de paiz hispano-mapuches du XVIIle siècle". HSAL, $n^{\circ} 7$, premier semestre 1998, 185-208.

Fuentes Inéditas:

Archivo Franciscano del Colegio de Chillán (AFCCh.) volúmenes 3, 10, 12, 14
Archivo Nacional, Fondo Capitanía General, volúmenes 315, 508, 537 y 665 .

Archivo Nacional, Fondo Judicial Valdivia

Archivo Nacional, Fondo Ministerio del Interior, vol. 250.

Archivo General de Indias (AGI) Chile 221. 